\title{
REFLECTIVE PRACTICE THROUGH MENTORSHIP: A PROGRAM REFLECTION
}

\author{
Emily Pottinger, Grand Canyon University \\ Rebekah Dyer, Grand Canyon University \\ Jena Akard, Grand Canyon University
}

\begin{abstract}
Reflection is an essential practice within the field of teaching. In addition, education is a profession that is in a constant state of flux as new research, theory, and policy is created. Because of this, teachers must continually evaluate, assess, and reflect in order to stay abreast with new initiatives, practices, and expectations within the classroom. However, maintaining this ever-changing knowledge requires collaboration. Both reflection practice and teaching practice benefit greatly through interactions and mentorships among colleagues. The following will explore and reflect upon how one college used a faculty mentorship program to improve adjunct faculty's reflective and teaching practices through collaboration. INTRODUCTION LITERATURE REVIEW

It is known that the teaching and learning cycle involves social components. This social aspect of teaching and learning is a common thread found within the social learning theory, Vygotsky's sociocultural theory, the Community of Inquiry (CoI), and more (Bandura \& Walters, 1977; Garrison \& Arbaugh, 2007; Tutunis \& Hacifazlioglu, 2018). More specifically, "Vygotsky's sociocultural theory of human learning describes learning as a social process and the origination of the human intelligence in society and culture. The theoretical framework is that social interaction plays a fundamental role in the development of cognition" (Tutunis \& Hacifazlioglu, 2018, p. 107). In addition, reflection is another key element necessary for effective teaching and learning (Harrison, Lawson, \& Wortley, 2005). Therefore, including collaboration and reflection among teachers and faculty should be seen as an essential component to ensure development and growth in the areas of teaching and learning at the university level. The following explores one college's solution to providing such social opportunities through mentorship. This paper will provide the literature and background, the model and implementation used by one college, and the reflection and impact upon this collaborative mentorship opportunity.

The following will examine a review of the literature regarding reflective practice and teaching, as well as the need for social interaction through mentorship within the teaching area of the teaching and learning cycle. The literature will explore the need for reflection, mentorship, and collaboration for faculty and their teaching practices. The sections below include (1) reflective practice, (2) mentorship and collaboration, and (3) social learning and connectivism.

Reflective Practice

Reflection and reflective practice are essential for teaching and education (Harrison et al., 2005). Specifically, Darling-Hammond (2008) stated that teachers best learn by studying, doing, and reflecting. This might occur within a teacher's own classroom, through observation of others' classrooms, and through dialogue of the teaching and learning occurring in those classrooms. In fact, it is known that a teacher's own classroom can be a powerful tool in the development and continuation of their own learning (Borko, 2004). For example, mentor teachers may bring and use materials, videos, and examples from their own classrooms in order to professionally develop and assist fellow teachers in their development. Therefore, teachers
\end{abstract}


and faculty can benefit from reflecting upon their own classrooms, as well as their own teaching and learning, in addition to the teaching and learning of their fellow colleagues.

\section{Mentorship and Collaboration}

Teachers and faculty must be multifaceted in order to consider the many components involved within the teaching and learning cycle. Effective teaching does not only require faculty to hold subject matter expertise, but there are a wide range of skills needed to successfully teach said subject matter. For example, it is essential that faculty have a variety of pedagogical skills. In addition, teachers and faculty require several kinds of knowledge about learning, such as how different materials might suit different students and learning purposes, as well as the need for a variety of teaching strategies, assessments, and more (Darling-Hammond, 2008). On top of the aforementioned expectations, teachers and faculty also must have a knowledge and deep understanding of curriculum, resources, technologies, and of course, a way to assess or evaluate the learning occurring in the classroom (Darling-Hammond, 2008). In order to develop such a wide variety of skills, research states that teachers learn best by simultaneously including a number of elements into their growth and development, such as seeing, doing, and reflecting upon their practice. In addition, there is a need for faculty and leadership support. For example, "Administrative support can drive the academic team to initiate and manage a new program, setting standards that will impact improved student outcomes, strengthen the culture, advance the mission, and enhance faculty job satisfaction" (Gies, 2013, p. 39). Therefore, collaboration with other teachers, faculty, and faculty leadership is a key component to teacher learning, specifically through examining and discussing lessons, student work, assessments, expectations, and so forth.

There is a need, in order for teachers to develop, to have access to opportunities to practice, test, research, and talk about what is occurring in their classrooms. To do so, success can be found in providing mentorship among teachers and faculty (Callahan, 2016). Studies show that using mentorship to assist in teaching practice and experience can lead to an effective reflective practice (Mena, Hennissen, \& Loughran, 2017). The mentor may be defined as that master teacher who may greatly understand the challenges and needs of a new teacher or faculty. In addition, the mentor can anticipate and assist in navigating difficult situations, cases, or obstacles (Callahan, 2016).

\section{Social Learning and Connectivism}

When reviewing the literature above regarding reflection, mentorship, and collaboration among teachers and faculty, a common social thread occurred. Bandura and Walters (1977) stated that new patterns of behavior can either be learned through direct experience or observing others. There is a social aspect to learning that should be identified within the teaching and learning practice among educators. In addition, there is a need for mental processing to occur prior to any sort of behavioral output. To allow for these social and mental processing components to occur, this is the ideal position to include both mentorship and reflection within the teaching and learning cycle.

While Bandura's social learning theory focused much of his work on children's learning, this concept is quite applicable to individuals of all ages and in a variety of fields, including that of education, teaching, and learning. The social learning theory showcases how individuals learn from one another, but technology today allows for connections to be made among peers and colleagues in a professional setting by using Web 2.0 tools, such as online learning management systems, websites, Flipgrid, Zoom video conferencing, and more. With this, further research has explored concepts such as social presence, such as that within the Community of Inquiry framework.

With this ever growing use of technology, there is a great influence upon the teaching and learning cycle. Fromhow to wherecontentistaught, technology is present. Because of this, there is a need to further understand how this can affect and influence the teaching and learning cycle in a traditional sense as well. In addition, there is a need to understand how current teachers and faculty use such concepts, like CoI, and tools, such as video conferencing, to better assist in their own professional development, particularly from a part-time, adjunct faculty lens. From this idea enters the conceptual framework of connectivism. Connectivism views "learning as a network phenomenon influenced by technology and socialization" (Goldie, 2016, p. 4). 
The literature supports the need for reflection, modeling, connections, collaboration, and mentorship among teachers and faculty. Therefore, because of this need, one college developed a mentorship program to assist in supporting the adjunct faculty community. The following section will discuss how this college applied this knowledge from the literature and prior experiences with faculty and collaboration to the development and implementation of one faculty mentorship model. This model and implementation section will examine processes, procedures, best practices, and more.

\section{MODEL AND IMPLEMENTATION}

Literature describes the need for reflective practice within the teaching and learning cycle. The following will explore one college's solution for the need to include reflection, collaboration, and connections through the use of a mentorship program. Sections will include the following: (1) processes and procedures, (2) best practice through mentorship and collaboration, and (3) best practice through reflection.

\section{Processes and Procedures}

In order to begin developing processes and procedures for a mentorship program, there was a need to examine the population. The college began by first analyzing all adjunct instructors within the college to determine a number of factors, such as the length of time in service to the college and university, evaluations, end-of-course survey results, and so forth. From this analysis, there was a determination that adjunct faculty required varying levels of support depending upon experience or number of semesters taught. For example, first semester adjuncts included newly hired adjunct faculty that may have had limited to no experience teaching at the university or at the collegiate level. From this, there were three groups or tiers for the adjunct faculty support divided by semester.

These tiers consisted of first semester, second semester, and third semester supports. Each tier received varying levels of support. First semester adjunct faculty received the highest level of support, including monthly meetings, formal peer support reviews, one announced or unannounced classroom visit, and one-on-one check-ins with a faculty mentor. Second semester adjunct faculty members were faculty with internal or external higher education experience at the faculty level.
Second semester adjunct faculty received the support through the monthly meetings, two announced or unannounced classroom visits, and a faculty mentor. Finally, adjuncts with two or more semesters of college-level teaching experience were invited to the monthly meetings and were often identified as a resource for new adjuncts. Adjunct faculty within the third tier also maintained access to faculty mentors. It is also important to note that adjunct faculty within this program held a variety of positions within the university as well as outside the university. For example, some roles held by adjunct faculty included those involved in the development of curriculum, online faculty positions, faculty development positions, PreK-12 grade teachers, principals, and so forth. Because of the wide variety of positions, it was essential that supports were provided through a number of modalities. The subsections below will describe these supports in the following subsections: (1) whole group meetings, (2) peer reviews, (3) oneon-one check-ins, (4) digital directory, and (5) digital tools.

Whole group meetings. The support processes included whole group meetings, one-onone check-ins, and peer support reviews. The whole group meetings included opportunities for the mentors and adjunct faculty members to meet together once a month either face-to-face or via technology with a follow-up email that included any reminders, expectations, and resources, along with a recording of the presentation. Adjunct faculty members could choose between a week day or weekend meeting, as it was important to allow for flexibility within schedules.

During these meetings, the mentors provided a number of items, such as university and college reminders, expectations, highlights, best practices, new strategies, reflections of personal practice (with a question and suggestion time), and opportunities for feedback through surveys. These communications were vital, as there were a number of large changes that occurred within the university and the college, such as accreditation and athletic status changes. These updates were important to share to not only ensure awareness of such changes, but to also ensure adjunct faculty felt connected to the university and college community. In addition to updates on changes, the university and college 
require all faculty to meet a variety of expectations, such as grade due dates, participation requirements, and other policies and procedures. While this information is also shared during adjunct faculty training, there are vast requirements. Therefore, there was a need to dissect and further examine best practices to ensure all faculty met all expectations.

While updates and expectations are vital to the success of the adjunct faculty, it is also essential to share best practices and teaching strategies. Some examples of best practices shared during the adjunct community meetings included concepts that might help support student engagement and discussion, such as Kagan strategies, Flipgrid (technology), and so forth. As it is known that faculty and teachers learn from one another, it was important to include self-reflections, and peer-topeer discussion when discussing best practices. Because of this, meetings included a time to share celebrations, challenges in the classroom, or ideas, resources, or strategies to improve teaching and learning. This was also an opportunity for mentors to notate particular trends, difficulties, and successes. Finally, each meeting ended with a survey asking adjunct members to provide feedback on the meeting (face-to-face, remotely, or recorded), as well as topics for future meetings. Mentors found great importance in ensuring that meetings were faculty and data driven.

Peer reviews. Following the first few weeks, but allowing for the adjunct faculty member to acclimate to the classroom, the mentor would schedule a peer review. This university process included a pre-conference, classroom evaluation, and post-conference. The peer review was developed and required by the university and used within all colleges. The pre-conference electronic form was completed with the adjunct faculty to provide specific context for the classroom evaluation. Once the pre-conference was complete, the mentors visited the class unannounced and provided feedback about the lesson observed. Following the classroom observation, the mentor would conduct a post-conference meeting. Each meeting called upon the adjunct faculty member to reflect on their own practice and highlight areas of strength and an area for growth. In addition, the mentors would provide feedback and suggestions regarding the teaching and learning observed.
The mentors also encouraged the adjunct faculty members to discuss the process with their students to discuss the continual improvement process, as this is helpful for modeling best practices within the classroom regarding self-reflection. Mentors also made themselves available to the adjunct faculty member for questions, comments, and/or concerns. Finally, reflection on this process was also encouraged during whole group meetings to discuss best practices and examples.

One-on-one check-ins. In addition to whole group meetings and more formalized peer reviews, there was also a need for a less formal check-in process among adjunct faculty to ensure success, growth, and community. The one-on-one checkins included a welcome email from the mentor, invitation to the Remind app (a text messaging system for quick communication) for the group, and self-reflection on areas to focus for the semester. The one-on-one mentorship allowed for more specific alignment of expertise whenever possible to allow for more refined and content specific feedback during classroom visits, discussions, and so forth. The mentors either communicated via email, text, video technology (Zoom), and/or phone conversation to determine the adjunct faculty's goal or area of focus each semester. Again, it was essential that the mentorship be tailored to meet the needs of individual adjunct faculty. Individualized support included, but was not limited to, brainstorming strategies to accomplish goals, providing examples, tips, and tricks, as well as opportunities for modeled strategies during observations with mentors or other faculty experts.

Digital directory. In addition to the various supports provided, a digital college directory was created and included full-time ground and online faculty, as well as adjunct faculty. The creation of the digital college directory was developed to encourage a sense of community among all college faculty members. The goal was to improve everyone's practice through awareness, collaboration, areas of expertise, and research interests. The directory was in alphabetical order to make the faculty easy to find and no division among the groups (i.e., ground, online, and adjunct), promoting one College of Education. The directory included a picture of the faculty member, degrees, areas of expertise, and research interests. 
The directory served as a reference for all who taught in the college.

Digital tools. While there were a variety of support strategies used within this mentorship program, it is important to identify how technology was used to enhance relationship, collaboration, and reflection. There were many digital technologies that were used throughout the mentorship. The goal through the different technologies was to develop a collaborative environment. In order to conduct the whole group meetings, video technology was incorporated, and these included Zoom, YouTube, and Loom. PowerPoint was used to organize and present the information at the meetings. Survey Monkey and Google Forms were used to survey the adjunct faculty members who participated. Email and Remind were used to send meeting reminders, Zoom meeting links, as well as other additional tools, tips, and resources. Each of these digital tools were discussed during meetings as opportunities to not only engage with one another, but to also engage learners within their own classrooms. Additional learning digital tools, such as Flipgrid and Kahoot, were also discussed as engagement strategies and best practices within the classroom.

\section{Best Practice through Mentorship and Collaboration}

Gies (2013) noted the challenge from transition from a practitioner to an instructor in the nursing field, and this is similar to the field of education too. This college faculty mentorship program provided the opportunity for participating adjunct faculty to identify a professional goal (content or methodological). Adjunct faculty mentors provided support in those professional goals through practice, practical application, testing, and/or research. In addition, this experience provided colleagues ample opportunities for discussion and reflection throughout the mentor process. This mentorship program provided adjunct faculty an opportunity to have a collaborative conversation with another professional within the field to improve professional and teaching practice. This collaboration took many forms based on the adjunct faculty member's need and may have involved, but was not limited to, the mentor, additional faculty members, and college leadership. Collaborative experiences ranged from team planning, observing mentors or other faculty members teaching, reflective "debriefing" conversations to co-teaching and more.

\section{Best Practice through Reflection}

Adjunct faculty enter their role with varying levels of experience in higher education, ranging from years of experience to none at all. Despite this, it is vital to note the level of expertise and unique experiences brought by each adjunct faculty member as it plays a role within reflection and teaching future teachers. The concept of reflecting deeply about the concepts they teach to future teachers and the specific strategies they employ to teach the concept has to be evident to the future teachers. This constant reflective practice is vital to understanding their own teaching (Jeppesen \& Joyce, 2018) and ultimately sharing that with future teachers. The college instructor needs to teach content, instructional strategies, and how to be a reflective practitioner. This skill of reflecting often is surface level, noting if it was a good or bad lesson and either feeling positive or negative about teaching abilities. Diving deeper and learning from experiences and lessons, whether good or bad, will allow for growth and future teaching success. As university faculty members of future educators and professionals, it is essential to demonstrate and model best practices, including self-reflection and reflection with peers. In addition, it is key to provide a wide array of examples of reflection throughout the teaching and learning cycle. For example, reflection can occur in an on-the-spot recap of a particular lesson that results in monitoring and adjusting a particular activity, or reflection may occur in a more in depth review and discussion following a lesson. While there are a number of benefits involved in mentorship and reflection, the goal of successful and effective mentorship is good teaching practice which can lead to an increase in student success (Parker, Brown, \& Holmes, 2019). Therefore, reflecting on individual and best teaching practice was a key focus throughout this mentorship program.

\section{REFLECTION}

The adjunct mentorship program was conducted from the fall semester of 2016 to the fall semester of 2018, and included over 30 adjunct faculty instructors. Data was collected throughout the adjunct mentorship program to determine the effectiveness of the meetings that were held and 
gave the adjunct faculty an opportunity to reflect, ask more questions, and share what they learned in the meeting. The data was collected with a survey at the end of each meeting through either Survey Monkey or a Google Form. The meeting participants were provided with a link and $\mathrm{QR}$ code to access the survey by either their phone or computer. The mentors reviewed the results of the surveys to determine what type of additional support might be needed for the adjunct faculty, what was going well with the program, and overall feedback on the meetings.

The meetings that were offered for the adjunct faculty were in-person or through Zoom video conferencing. The number of participants for the in-person meetings was significantly lower than the meetings through Zoom. The number of participants that responded to the survey after each meeting varied, but there was never $100 \%$ participation. The survey questions varied each time.

Participating in the adjunct mentorship program allowed the adjunct faculty to collaborate with their peers within the college. They were able to get teaching ideas from each other, their mentors, and other full-time faculty. The mentors discussed being proactive in getting feedback from students with the adjunct faculty. This encouraged the adjunct faculty to review that feedback, reflect on their teaching, and make adjustments if needed. In addition, the meetings with the adjunct faculty included a lot of reminders, review of university policies, action steps for plagiarism issues, a list of people to go to with questions, and information on logistics of teaching the courses.

The results of the adjunct mentorship program demonstrated a positive impact on the success of the adjunct faculty. Adjunct faculty were not only observed by their mentors, but adjunct faculty were provided opportunities to observe their mentors teach, and some experienced co-teaching or teamteaching opportunities as well. In addition, some adjunct faculty were able to observe one another or additional faculty within the college. The mentor provided feedback on their observation and provided the adjunct faculty with an opportunity to reflect on their own practice. Communication regarding feedback, reflection, and the mentor model included, but was not limited to, emails from adjunct mentor program participants to their mentors providing feedback on the program, surveys responses from participants, and synchronous face-to-face, phone, and Zoom meeting conversations.

Another positive result of the adjunct mentorship program was with adjunct faculty continuing on to additional roles within the university, such as full-time faculty, subject matter experts, peer reviewers, faculty trainers, curriculum developers, and so forth. It was found beneficial for adjunct faculty to have participated in the adjunct mentorship program within varying roles, particularly as it related to faculty. Participants developed many tools through the mentorship program and developed relationships with other faculty members. This assisted participants in successful transitions into alternate positions, such as full-time faculty members.

The surveys that were conducted included a question for the adjunct faculty to express what they would like to have covered in future meetings. A few examples of feedback provided were the following: (1) adjunct faculty would like more information on how to group students for engaging activities; (2) adjunct faculty wanted more information on the academic program in which they were teaching; and (3) adjunct faculty requested a map of the program so that they could see where their particular course fell within the student's progression of learning. Because the adjunct faculty were provided this opportunity, many requests were quickly addressed with resources and tools already established by the university and college. However, for those requests or suggestions that required further exploration, this feedback provided opportunity for further college reflection.

Overall, the data that was collected throughout the adjunct mentorship program was consistently positive. The adjunct faculty were able to make connections with full-time faculty, faculty that taught similar courses, leaders within the college, and other departments within the university. As new adjunct faculty members, they had a vast amount of information to learn about their role, and the adjunct mentorship program provided them with the opportunity to remain informed, as well as continuously reflect and adjust if needed. Because of the overall success of this program, as well as the relationships developed, the researchers see opportunity for further examination and research 
to uncover additional information regarding the power of reflection through mentorship on the development of adjunct faculty in the university setting. Future research may include components such as more formally collected quantitative and qualitative data to support the above reflections and anecdotal information provided on mentorship programs such as the one described in this article.

\section{CONCLUSION}

This paper provided the literature, the background, and an example of one college's solution on the need for reflective practice within the teaching and learning cycle, particularly as it pertains to teachers and faculty in their development. As described in the literature, there are a number of expectations that teachers and faculty must address and meet within their classrooms. Therefore, ample supports must be provided to ensure optimal growth for teachers and faculty to ensure effective teaching and learning might occur. To meet this need, one college sought to infuse mentorship and reflection through mentorship within their adjunct faculty community. This model allowed for faculty learning to be a social process through interactions with fellow faculty and mentors. In addition, as it is known that reflection is a key element for effective teaching and learning, this collaborative environment fostered self-reflection as well as the reflection of others' input, experiences, examples, and so forth. The college saw this experience as an essential component to ensure adjunct development and growth in the areas of teaching and learning when teaching courses at the university level. However, it is suggested that further research examine programs such as these and the effects and benefits upon adjunct faculty's growth, reflection, and practice within the university environment. 


\section{REFERENCES}

Bandura, A., \& Walters, R. H. (1977). Social learning theory (vol. 1). Englewood Cliffs, NJ: Prentice Hall.

Borko, H. (2004). Professional development and teacher learning: Mapping the terrain. Educational Researcher, 33(8), 3-15. doi. org/10.3102/0013189X033008003

Callahan, J. (2016). Encouraging retention of new teachers through mentoring strategies. Delta Kappa Gamma Bulletin, 83(1), 6 .

Darling-Hammond, L. (2008). Teacher learning that supports student learning. Teaching for intelligence, 2(1), 91-100.

Garrison, D. R., \& Arbaugh, J. B. (2007). Researching the community of inquiry framework: Review, issues, and future directions. The Internet and Higher Education, 10(3), 157-172.

Gies, M. L. (2013). Mentoring clinical adjunct nursing faculty. International Journal for Human Caring, 17(3), 35-40.

Goldie, J. G. S. (2016). Connectivism: A knowledge learning theory for the digital age? Medical teacher, 38(10), 10641069.

Harrison, J. K., Lawson, T., \& Wortley, A. (2005). Mentoring the beginning teacher: Developing professional autonomy through critical reflection on practice. Reflective practice, 6(3), 419-441.

Jeppesen, A., \& Joyce, B. (2018). Challenges and successes: Faculty reflections on a college teaching development program. Collected Essays on Learning and Teaching, 11, 1-10.

Mena, J., Hennissen, P., \& Loughran, J. (2017). Developing preservice teachers' professional knowledge of teaching: The influence of mentoring. Teaching and teacher education, 66 , 47-59.

Parker, D. M., Brown, L. T. M., \& Holmes, B. D. (2019). Preparing university adjunct faculty to teach. Journal of Higher Education Theory \& Practice, 18(7), 115.

Tutunis, B., \& Hacifazlioglu, O. (2018). The impact of reflective practices of English language teachers on the development of a sense of agency. Journal of Education and Training Studies, 6(10), 107-116. 